\title{
Requirements for a Helium- Cooled Blanket Heat Removal System Development Facility for Fusion Reactor Research
}

by
A. M. Sutey
F. R. Zaloudek
H. J. Bomelburg

August 1977

Prepared for the Energy Research and Development Administration under Contract EY-76-C-06-1830 
NOTICE

This report was prepared as an account of work sponsored by the United States Government. Neither the United States nor the Energy Research and Development Administration, nor any of their employees, nor any of their contractors, subcontractors, or their employees, makes any warranty, express or implied, or assumes any legal liability or responsibility for the accuracy, completeness or usefulness of any information, apparatus, product or process disclosed, or represents that its use would not infringe privately owned rights.

The views, opinions and conclusions contained in this report are those of the contractor and do not necessarily represent those of the United States Government or the United States Energy Research and Development Administration.

\author{
PACIFIC NORTHWEST LABORATORY \\ operated by \\ BATTELLE \\ for the \\ ENERGY RESEARCH AND DEVELOPMENT ADMINISTRATION \\ Under Contract EY-76-C-06-1830
}

\author{
Printed in the United States of America \\ Available from \\ National Technical Information Service \\ U.S. Department of Commerce \\ 5285 Port Royal Road \\ Springfieid. Virginia 22151
}

Price: Printed Copy 5 $\because$ Microfiche $\$ 3.00$

$\begin{array}{cc}\text {-Pages } & \begin{array}{c}\text { NTIS } \\ \text { Selling Price }\end{array} \\ 001-025 & \$ 4.50 \\ 026-050 & \$ 5.00 \\ 051-075 & \$ 5.50 \\ 076-100 & \$ 6.00 \\ 101-125 & \$ 6.50 \\ 126-150 & \$ 7.00 \\ 157-175 & \$ 7.75 \\ 176-200 & \$ 8.50 \\ 201-225 & \$ 8.75 \\ 226-250 & \$ 9.00 \\ 251-275 & \$ 10.00 \\ 276-300 & \$ 10.25\end{array}$




\section{5}

BNWL -2301

UC-20

REQUIREMENTS FOR A HELIUM-COOLED

BLANKET HEAT REMOVAL SYSTEM

DEVELOPMENT FACILITY FOR

FUSION REACTOR RESEARCH

by

A. M. Sutey

F. R. Zaloudek

H. J. Bomelburg

August 1977

BATTELLE

Pacific Northwest Laboratories

Richland, Washington 99352 
Existing and potential design problems associated with the helium-cooled blanket assemblies of experimental, demonstration and hybrid reactor designs considered in the Magnetic Fusion Energy (MFE) Program were assessed. It was observed that a balanced program of design, analysis and experimentation would be required to develop, verify and qualify these designs and those of related hardware and equipment. To respond to the potential experimental requirements of the first-generatior reactors (the EPRs and possibly the hybrid concept), the need for a helium test facility was identified. It was determined that this facility should have the capacity for recirculating $100,000 \mathrm{~kg} / \mathrm{hr}$ of helium at $70 \mathrm{~atm}$ and $600^{\circ} \mathrm{C}$ and should have $3 \mathrm{MW}$ of electrical power available for simulating neutron heating. No radioactive material or processes should be used to facilitate "hands-on" experimentation and development. The general types of testing anticipated in this facility would include:

- thermal and coolant flow performance of the blanket and other components in the primary cooling circuit;

- structural adequacy of the blanket and first wall including vibration considerations;

- capability for accommodating safety/off-normal conditions.

Existing facilities worldwide were surveyed. It was determined that a number of facilities exist in foreign nations for performing the anticipated experiments. However, no large helium gas flow loop exists within the U.S.A. Consequently, it is recommended that a helium thermal-hydraulic ilanket test facility be planned and built on a schedule that will meet the unique design developmient and verification needs of the fusion program. This report provides the rationale and prei iminary scoping of the operationai characteristics and requirements for such a facility. 


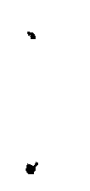

,

. 


\section{CONTENTS}

SUMMARY

1.0 INTRODUCTION

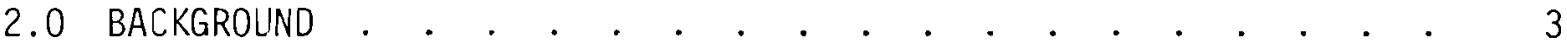

2.1 THE D-T FUSION REACTION . . • • . . . • . . . . . . . 3

2.2 MAGNETIC FUSION REACTOR COMPONENTS . . . . . . . . . . . 3

2.3 THE BLANKET . . . . . . . . . . . . . . . . . . . . . . 5

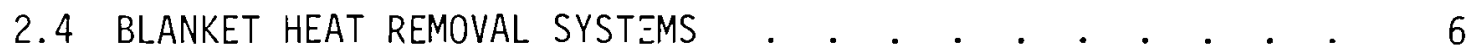

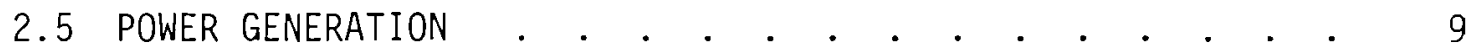

3.0 THERMAL PROBLEMS OF HELIUM-COOLED BLANKET DESIGNS FOR

EXPERIMENTAL AND DEMONSTRATION REACTORS . . . . . . . . . . 11

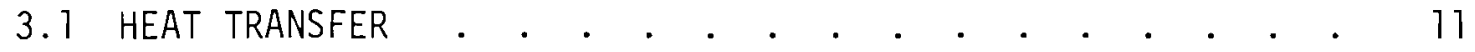

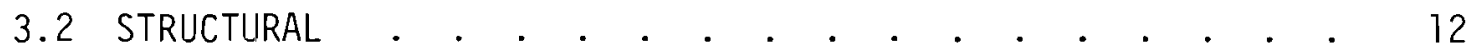

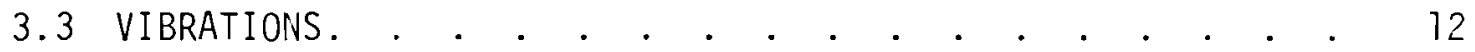

3.4 CORROSION • .

3.5 INSTRUMENTATION AND CONTROL . . . . . . . . . . . . . . 14

3.6 DESIGN VERIFICATION AND COMPONENT QUALIFICATION $\quad$ • . . . 14

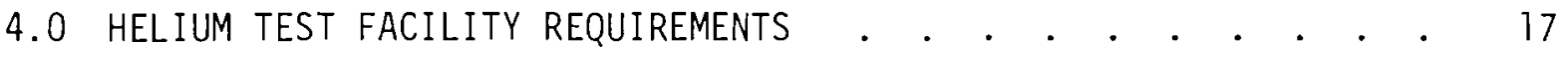

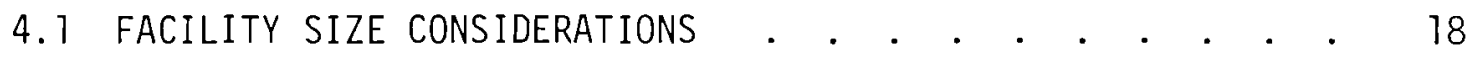

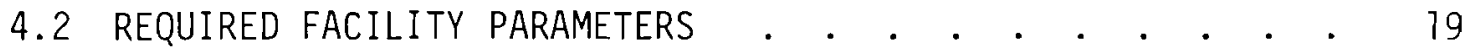

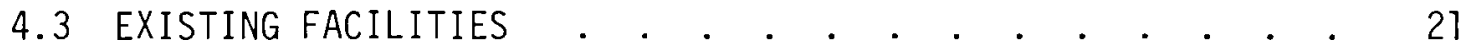

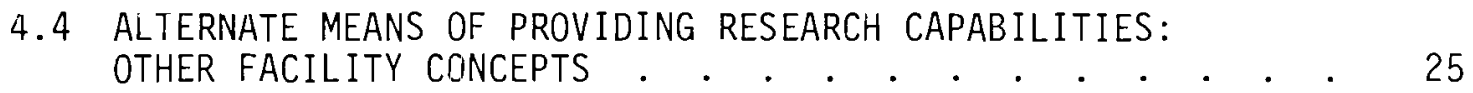

5.0 RECOMMENDED HELIUM-COOLED BLANKET DEVELOPMENT FACILITY. . . . 27

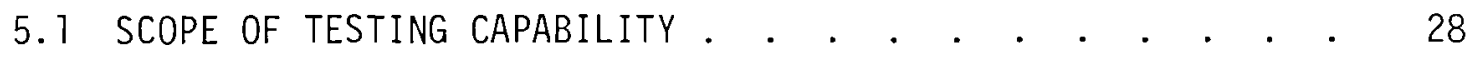

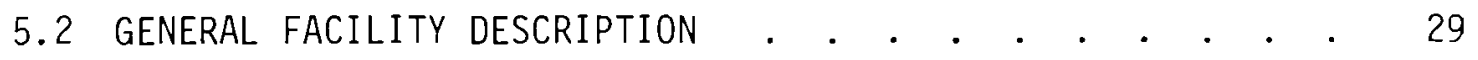

5.3 BLANKET AND FIRST WALL SIMULATION • • • • • • • • • • 32

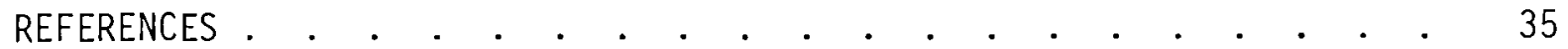




\section{FIGURES}

1 Helium Flow Tubes for Cooling the Liquid Flibe Blanket of the PPPL Tokamak Design. . . . . . . . . . . . . . . . 8

2 Blanket Section for the UWMAK-II Tokamak Design. . . . . . . 9

3 Section Views of a Module from the BNL Blanket Design. . . . . 10

4 HHV Facility Flow Diagram . . . . . . . . . . . . . . 24

5 Facility Schematic . . . . . . . . . . . . . 30

\section{TABLES}

1 Preliminary Blanket Design Parameters for Helium-Cooled

Experimental and Demonstration Power Reactors, U.S. Magnetic

Fusion Energy Program . . . . . . . . . . . . . . . 7

2 Technical Requirements for Testing Single Blanket Modules . . 20

3 High Temperature Gas Loops for Testing Reactor Components . . . 23 


\section{REQUIREMENTS FOR A HELIUM-COOLED BLANKET HEAT REMOVAL SYSTEM DEVELOPMENT FACILITY FOR FUSION REACTOR RESEARCH}

\subsection{INTRODUCTION}

Although there are many technological obstacles in the path of commercial fusion power development, sufficient progress has been made to expect the laboratory demonstration of meaningful levels of the D-T reaction in the mid-1980s. Following a successful demonstration, it is expected that experimental and demonstration power reactors (EPRs and DPRS) could be constructed and in operation Defore the year 2000. Commercial operation of large fusion power plants could occur as early as 2010.

Many of the technological obstacles are directly associated with the production of the fusion reaction, and most of the research and development performed to date has been directed toward this area. There are other areas in which formidable research, engineering and development problems exist, which will be given increasing attention in coming years. One such area is the blanket structure.

The blanket structure is normally placed between the plasma and magnetic coils to slow down the $14.1 \mathrm{MeV}$ neutrons from the fusion reaction and to convert their kinetic energy into heat for use in a thermal power cycle. The blanket also may contain a fertile material (1ithium-bearing) to breed tritium. A cooling fluid must be circulated through the blanket to keep it cool and to transport the heat to the power cycle. Although several fluids have been proposed, helium appears to be favored for initial experiments and demonstrations.

Some especially difficult heat transfer and thermal-hydraulic design problems are associated with the blanket and especially the "first wall" of the blanket. Due to the proximity of the first wall to the plasma, a relatively high fraction of the fusion energy can be deposited in it, particularly during any abnormal operating conditions. This potential high energy deposition requires the development of a particularly effective cooling method to assure acceptable component lifetimes. In addition, pulsed fusion reactor 
designs impose both steady and cyclic thermal and mechanical forces on the blanket. Under such cyclic conditions, the three-dimensional temperature distributions and thermal stresses in the complex blanket structure are difficult to predict reliably.

The specific potential problems associated with the development of blanket designs for the experimental and demonstration reactors have been examined in several reports. $(1,2,3)$ It was generally concluded that the complex problems involved in such an effort must be supported with an aggressive experimental program. This program must include, among other things, 1) evaluation of the dynamic aspects of the cooling system performance and 2) evaluation and verification of the structural integrity of candidate blanket designs under the demanding thermal conditions imposed by the fusion reaction.

This report examines the experimental requirements for thermal-hydraulicstructural testing for EPR and DPR designs and defines the general functional characteristics for a helium-cooled testing facility that will be responsive to these requirements. 


\subsection{BACKGROUND}

Designs for various EPRs and DPRs under consideration in the Magnetic Fusion Energy Program are currently being actively developed. Characteristic of any development area, specifications, operating data and schedules are continuously changing. However, all plants under active consideration are functionaliy similar. Therefore, to provide background information, these designs will be described principally on the functional basis. Details will be discussed only when pertinent to the definition of test facility parameters.

\subsection{THE D-T FUSION REACTION}

Although a number of fusion reactions are possible, the $D-T$ reaction is least difficult to attain and has been selected for the early experimental and demonstration projects. This reaction is:

$$
1^{D^{2}}+1_{1} T^{3} \rightarrow{ }_{2} \mathrm{He}^{4}(3.5 \mathrm{MeV})+\mathrm{n}(14.1 \mathrm{MeV})
$$

In this reaction, $80 \%$ of the reaction energy is in the form of $14.1-\mathrm{MeV}$ neutrons and the remaining $20 \%$ is in the kinetic energy of the alpha particles. In all D-T-fueled fusion power plant designs, a fusioning D-T plasma is confined, heated and fueled. The neutron and radiation energies are captured and converted into heat in the blanket surrounding the plasma, and this heat is removed by a recirculating fluid. In power-producing designs this heat is transported to a thermal-cycle generating system. Tritium is recovered from remaining unburned plasma and from lithium-containing blanket materials for recycling to the plasma.

\subsection{MAGNETIC FUSION REACTOR COMPONENTS}

The eight principal systems in a magnetic fusion reactor are the:

- plasma confinement system

- plasma production system

- fuel system

- blanket

The plasma confinement system holds the fusioning plasma together long enough to release more fusion energy than is expended in creating the plasma. 
The plasma is confined within a "magnetic bottle" produced by magnetic coils. There are currently two principal magnetic field geometries. The Tokamak and the Theta-Pinch geometries can be described as toroidal; the Mirror machine yin-yang coils have interlocking $\mathrm{C}$-coils which produce a roughly spherical plasma geometry.

The plasma production system delivers large amounts of energy to the plasma, heating it to the high (near solar) temperature needed for fusion. Proposed heating methods include combinations of ohmic, adiabatic compression and neutral beam injection. A neutral beam injector is proposed for use in a 11 Mirror machines and most Tokamaks. It consists of an ion source, accelerator and a neutralizer. On Mirror machines and driven Tokamaks, the injector will be operated continuously; on ignited Tokamaks, intermittently.

The fuel system prepares and introduces the fuel into the plasma chamber at the appropriate time, temperature and velocity.

The blanket is one of the more important parts of the energy recovery system associated with a fusion reactor. The blanket is generally the structure between the plasma and the magnetic coils. Its prinicpal function is to slow down the 14.1-MeV neutrons from the fusion process and convert their kinetic energy into heat for use in a thermal power cycle. The blanket also contains a fertile material (lithium) to enable breeding of tritium fuel. The blanket is provided with an elaborate system of internal passages through which a coolant is circulated to keep the.blanket cool. The blanket will be discussed further in Section 2.3.

The cooling system recirculates the coolant through the blanket and transports the heat to the thermal power cycle for conversion into electricity. Various coolants currently being considered include 1 ithium, sodium, potassium, $\mathrm{LiAlO}_{2}$, flibe (LiF and BeF 2 mixture) and helium. Hei ium appears to be the favored coolant for current EPR and DPR designs. (1) The cooling system may transfer the heat from the coolant directly to a conventional steam power plant or through an intermediate heat exchange system.

The spent plasma recovery system collects escaping plasma particles during operation and recycles most of them to the plasma for consumption of the unburned fuel. 
The tritium recovery system removes the bred tritium from the fertile material in the blanket and returns it to the fuel system.

\subsection{THE BLANKET}

In addition to providing a vacuum chamber for plasma production, the blanket has a very important role in extracting and utilizing the energy produced by the fusion reaction. As described earlier, the 14.1-MeV neutrons escape from the plasma in all directions. The principal purpose of the blanket is to slow down these neutrons and to convert their kinetic energy into heat for use in a thermal power system. The blanket also receives energy in the form of gamma radiation that occurs from $(n, \alpha)$ reactions and, to a lesser extent, from the decay of radioactive materials. Therefore, a blanket will contain a neutron moderator material and a circulating cooling system to remove the heat for transport to the power system. An equally important function of the blanket is to breed tritium for use as fuel. Such breeding is necessary because the isotope ${ }_{T} T^{3}$ necessary for fueling the $D-T$ cycle does not occur in nature in substantial quantities. Tritium production is accomplished by including a lithium-bearing material in the blanket structure or in the coolant. The reactions involved are:

$$
\begin{aligned}
& 3^{L^{6}+n}={ }_{1} T^{3}+{ }_{2} \mathrm{He}^{4}+4.78 \mathrm{MeV} \\
& 3^{L^{7}+n}={ }_{1} T^{3}+{ }_{2} \mathrm{He}^{4}+\mathrm{n}^{1}-2.47 \mathrm{MeV}
\end{aligned}
$$

The "first wall" is the surface of the blanket closest to the plasma. This first wall, because of its proximity to the plasma, receives a relatively high fraction of the fusion energy in the form of radiant energy, the energy from impinging atoms and ions, and from neutron moderation. The neutron energy deposition in the remainder of the blanket falls off rapidly, depending on the distribution of the moderator in the structure. Because of the large heat loads on the first surface, it is important that it be adequately cooled to prevent rapid failure, especially during abnormal operating conditions. In some designs a shield is included to protect the first wall. In one concept, this shield is constructed of carbon cloth and cooled by radiation to the first wall (UWMAK-II and III). In another, the shield is constructed from thin wall tubing and cooled by high velocity, nucleate boiling water. 
Because no tritium breeding is planned in the EPRs, no moderator is included in the blankets. Therefore, the EPR blankets are somewhat simpler than those contemplated for the DPRs in which breeding is planned.

\subsection{BLANKET HEAT REMOVAL SYSTEMS}

Coolants considered for blanket cooling include lithium, sodium, potassium, flibe, $L \mathrm{LAlO} \mathrm{O}_{2}$, helium and water.

Perhaps some of the more interesting of these cooling materials are lithium and the lithium-bearing compounds, since they can perform all required blanket functions simultaneously, i.e., neutron moderation, cooling and tritium breeding. However, these substances are electrically conductive and are subject to influence by magnetohydrodynamic effects. The accompanying design problems are formidable and have led to proposals for other coolants, notably helium and water for all of the earlier reactors.

Helium has been particularly attractive because of its advantageous properties and the availability of a we1l-developed technology for its use as a cooling medium resulting from fission reactor (HTGR) experience. Its advantageous properties include chemical inertness, high heat transfer capabilities, negligible nuclear activation and zero magnetic susceptibility at high temperatures. Disadvantages include high required pumping power, need for large flow passages and pipe (in comparison to liquid metals) and a propensity for leakage through minute defects in the pressure boundary.

Table 1 lists helium-cooled EPRs and DPRS in the U.S. Magnetic Fusion Energy Program. Included are the reactors' principal design parameters. It should be noted that the first wall heat flux is generally low (2 to $100 \mathrm{~W} / \mathrm{cm}^{2}$ ) in comparison to anticipated cormercial plants' thermal loading, which may vary from 100 to $1,100 \mathrm{~W} / \mathrm{cm}^{2}$. (4) 


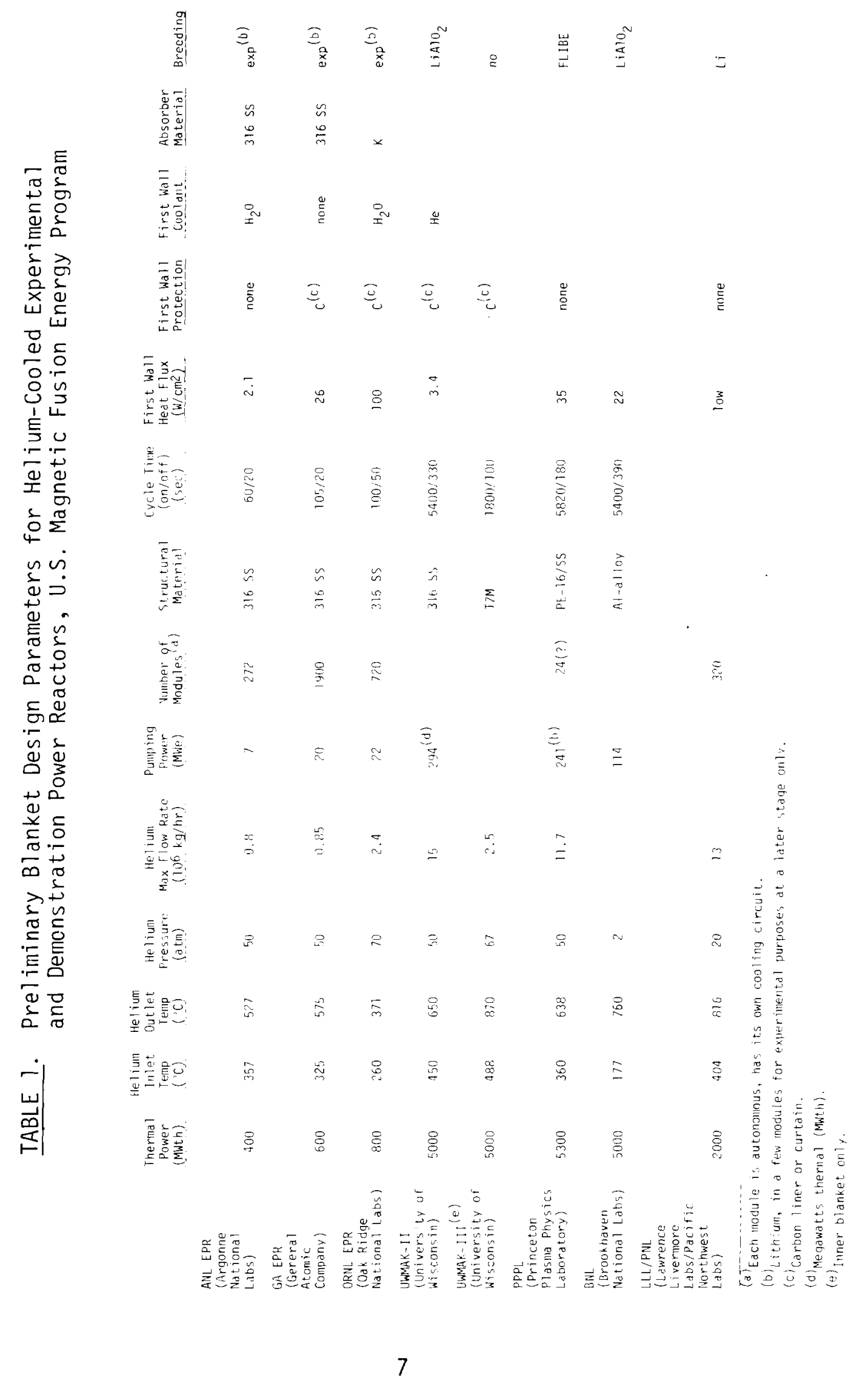


Figures 1 through 3 show some of the major features of the present blanket designs. Generally, blankets are modularized to facilitate replacement. These modules are complex structures and require an elaborate coolant supply and discharge header system to serve the multitude of modules in a reactor.

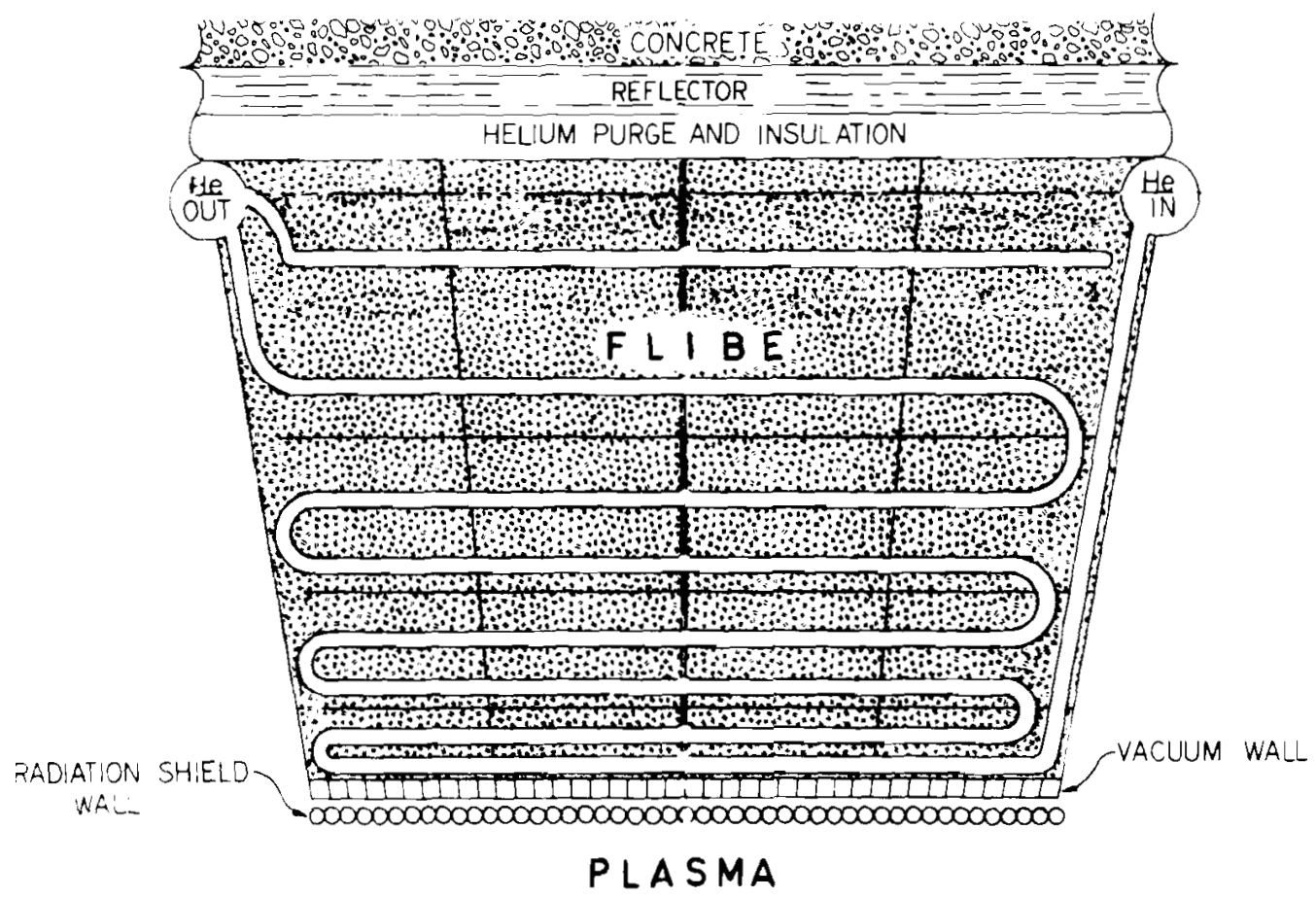

FIGURE 1. Helium Flow Tubes for Cooling the Liquid Flibe Blanket of the PPPL Tokamak Design 


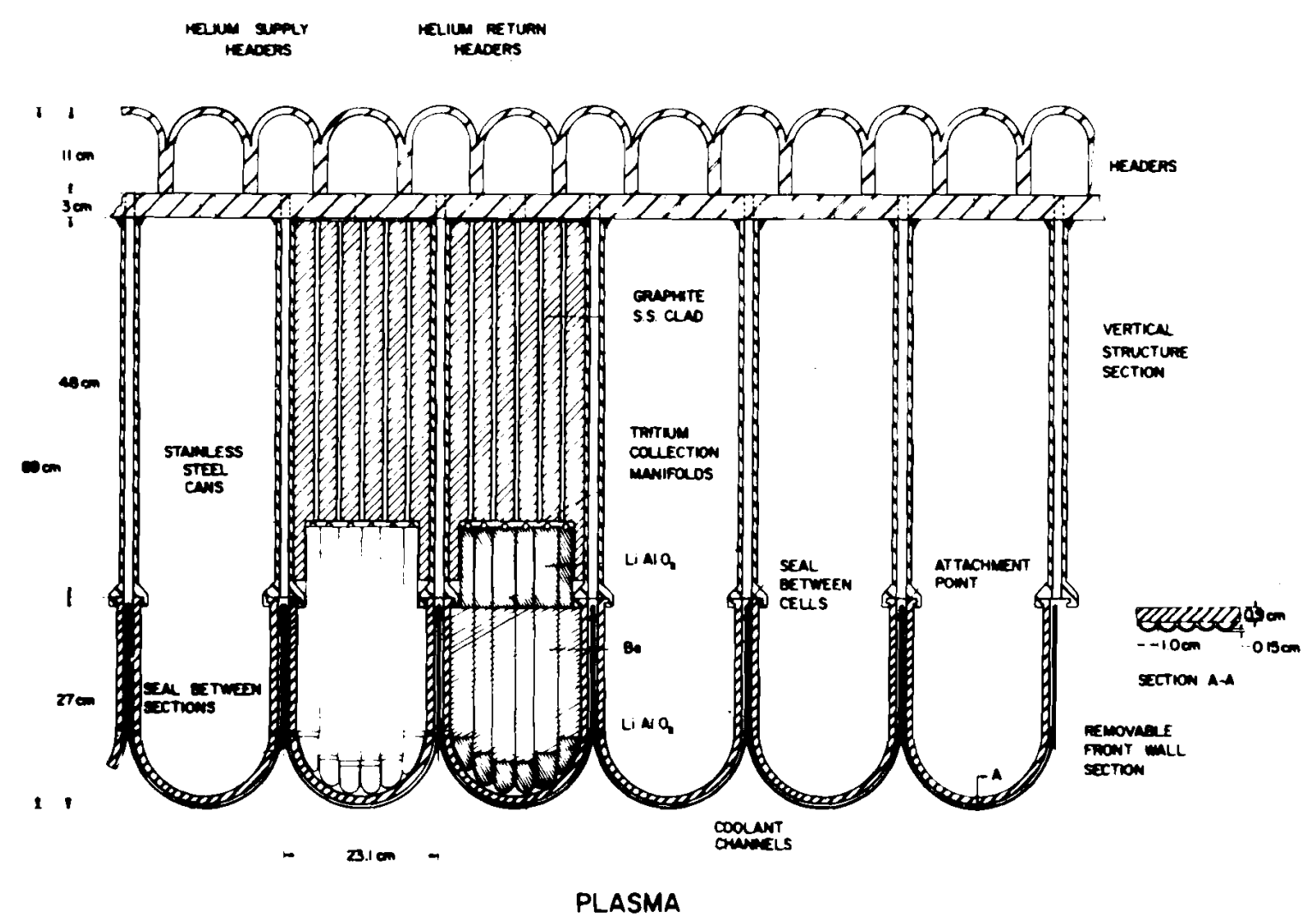

FIGURE 2. Blanket Section for the UWMAK-II Tokamak Design

\subsection{POWER GENERATION}

In power-producing fusion reactor designs, the blanket cooling system transports and rejects the heat produced in the blanket to a steam power cycle of a conventional or advanced design. In designs using liquid lithium as a primary coolant, an intermediate heat transfer system isolates the power plant from radioactivity present in the primary coolant and precludes violent chemical reactions in the steam generator if a steam generator leak should occur.

In helium-cooled blanket designs, intermediate heat transfer systems are not considered necessary for two reasons. Helium will not react with water, and radioactive materials carried in the coolant can be maintained at a much lower level than possible with lithium coolants. 


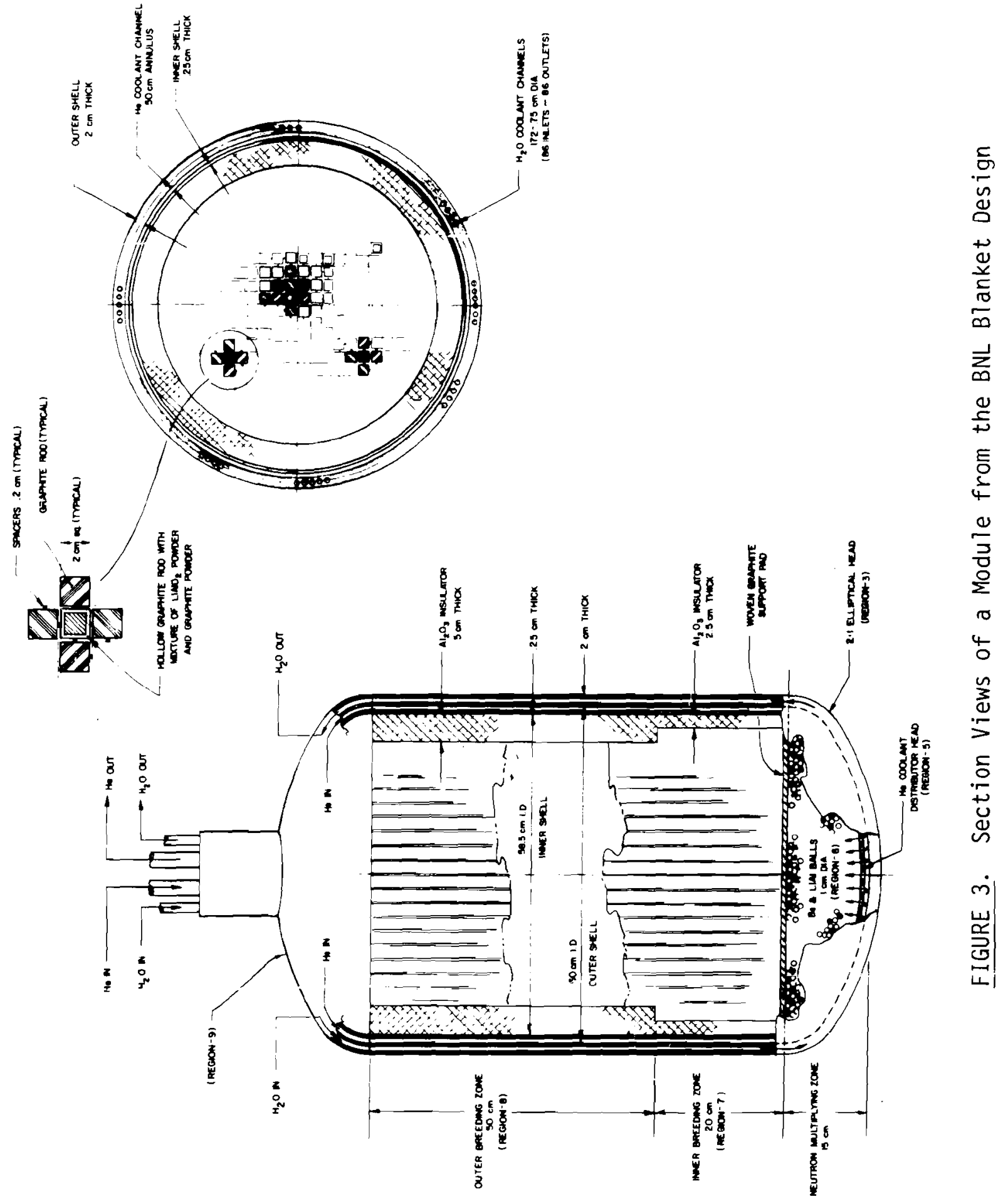




\subsection{THERMAL PROBLEMS OF HELIUM-COOLED BLANKET DESIGNS FOR EXPERIMENTAL AND DEMONSTRATION REACTORS}

The design and development of blankets and associated cooling systems has only recently been undertaken. So far, a number of potential thermal problems have been identified and discussed in several reports. $(1,2,3)$ As development proceeds, a number of additional problems are expected, requiring further attention.

In this section, some of the more important thermal problems requiring research and development will be identified and summarized. This is not intended to be a comprehensive analysis of these problem areas; readers interested in obtaining additional information should consult the indicated references. In this discussion, these problems will be categorized as:

- heat transfer

- structurar

- vibrations

- corrosion

- control and instrumentation

- verification and demonstration.

\subsection{HEAT TRANSFER}

As a result of HTGR development, the heat transfer and fluid dynamics technology of helium is already well advanced. It is generally believed that an adequate data base exists to satisfactorily design and analyze heliumcooled blanket concepts from the thermal-hydraulic standpoint. Therefore, it may be concluded that heat transfer or fluid dynamics aspects of helium alone may not be a problem. However, it should be noted that flow path geometries in fusion reactor designs are generally more complex than in HTGR and other applications and that the internal heat generation is much more nonuniform in time and in space. These conditions result in unusually large values of the temporal and space derivatives of temperature, leading to high thermal stresses and fatigue in the blanket components. Therefore, heat transfer and fluid dynamics must be considered as a vital adjunct of structural research and development activities. 


\subsection{STRUCTURAL}

The blanket of a fusion reactor is subjected to a very severe environment during operation. The high cyclical first wall power loadings produce thermal stresses and thermal strain cycling that could cause short blanket component lifetimes. Under off-normal conditions, hot spots can occur, causing large thermal gradients and high local stresses. The analysis of cyclic thermal stresses and fatigue life in the complex blanket structures is a very difficult problem. This problem is further complicated by the lack of good physical properties data on some of the candidate structural materials and welding materials as influenced by welding procedures, level of inspection and joint placement.

A design and development methodology involving an integrated analytic and experimental program will be necessary to produce a blanket design that could confidently attain goal lifetimes. The experimental program would necessarily include: 1) materials behavior tests in a high temperature helium atmosphere and 2) combined heat transfer and structural testing of the steady-state and cyclic response of candidate structures subjected to the pressure and thermal forces anticipated in prototype operation.

The same general statements can be made about structural equipment and components associated with the blanket such as bellows, seals, insulators, supports, penetrations, etc. Many of these components will be subjected to conditions similar to those experienced by the blanket, and corresponding reliable performance is required. The design of many of these components must be accomplished in a similar integrated analytic and experimental manner if the desired degree of dependability is to be assured.

\subsection{VIBRATIONS}

A potential for serious structural vibration can occur in fusion reactor blankets because of the cyclic nature of the process and the high coolant velocities required to remove the energy deposited in the blarkets. High coolant velocities can cause periodic forcing functions through the mechanism of vortex shedding, fluid-elastic interactions and turbulent buffeting. These forcing functions and cyclical process forces can interact with structura? 
natural frequencies to produce large amplifications of vibrational amplitudes. Vibrations can cause structural damage over periods of time through wear, fretting and fatigue of structural components.

Although flow-induced structural vibrations in simple heat exchangers have received much recent attention, the design and analys is of vibrations in complex cooling system structures such as a fusion blanket remains an art. In these complex structures it is common practice to perform forced vibration and flow tests to identify the natural frequencies of candidate structures and the sources and frequencies of excitation forces. In forced vibration tests, electromagnetic shakers are used to determine the natural frequencies and maximum amplitudes of candidate structure vibrations under prototype conditions. In the flow experiments, forcing functions and periodic forces exerted on the structure are determined by the use of accelerometers, strain gages and pressure tapes. If the obscured natural frequencies of vibration are not sufficiently higher than the potential excitation forces, designs are modified to provide the desired relationship.

It is expected that fusion reactor blanket assemblies will need to undergo long-term vibration testing to verify that structural lifetime is consistent with the service required for power production.

\subsection{CORROSION}

Although helium is itself inert, it may contain impurities which can lead to corrosion or other undesirable reactions. The impurities in the helium coolant in a fusion reactor may include $\mathrm{H}_{2}, \mathrm{H}_{2} \mathrm{O}, \mathrm{T}_{2} \mathrm{O}, \mathrm{CO}, \mathrm{CO}_{2}, \mathrm{CH}_{4}$ and $\mathrm{N}_{2}$ at partial pressures between 1 to 1000 atm. (1) These impurities may cause oxidation, carbonization, nitriding or hydriding reactions at elevated temperatures, potentially affecting the materials' properties. Experimental information must be obtained on the effects of these impurities on irradiated and nonirradiated construction materials to verify materials selection and fabrication methods and to assure that goal lifetimes will be attained. Much of this experimental effort could be performed with coupon samples. Final verification may be required with simulated modules to include the effects of coincident temperature and velocity fields in a prototype structure. 


\subsection{INSTRUMENTATION AND CONTROL}

The development of instrumentation and sensors which could be used to define the thermal performance of the blanket assembly during operations appears necessary. Such instrumentation will measure:

- first wall temperatures

- cooling temperatures

- coolant flow rates

- coolant pressures

- coolant composition.

In addition, other instrumentation or instrumentation leads must penetrate the blanket to sense plasma parameters.

Many of these sensors will be required to function reliably for extended periods in high neutron fields, high temperatures, sharp temperature gradients, in the high velocity coolant and when subjected to strong electrical and magnetic fields. It is anticipated that considerable R\&D will be required to develop such instrumentation. This R\&D must include experimentation to define the performance of this instrumentation in: 1) magnetic fields, 2) neutron fields, and 3) combined temperature and force fields resulting from nonuniform heat generation, fluid drag forces and differential expansion in the blanket. The third-mentioned experimentation may have to be performed in models of candidate modules or portions thereof.

\subsection{DESIGN VERIFICATION AND COMPONENT QUALIFICATION}

Each EPR and DPR design taken to the construction and operational phases constitutes a very costly and complex venture. Prior to construction, there must be a high level of confidence that all reactor components will function as specified and that no "surprises" will be encountered which may set back the MFE program. Therefore, it is important that each component and system undergo qualification and design verification to attain this level of confidence.

With regard to the various blankets, this qualification could consist of the nonnuclear testing of one module or meaningful module section at conditions of pressure, temperature, helium flow rates and heat generation 
simulating predicted prototypic service. Heat loads at the first wall and in the blanket may be simulated by plasma torches or electrical heating. In the absence of neutron and magnetic fields, it would be possible to make detailed measurements of temperature, pressure, strain and deflection under simulated steady-state and cyclic conditions. Long-term sustained operation can be maintained to verify lifetime requirements established from fatigue and corrosion considerations.

The above need for design verification and qualification of the blanket assembly modules is consistent with the findings and recommendations of the Magnetic Fusion Energy Blanket and Shield Workshop. (1)

Other components and ancillary equipment associated with the blanket may require similar qualification at simulated service conditions. Such components include bellows, seals, insulators, supports, penetrations, instrumentation, etc. Ancillary equipment includes helium cleanup systems, recirculators and steam generators. Each component and system must demonstrate the capability to perform satisfactorily under the most severe conditions anticipated and must exhibit the specified service life. 



\subsection{HELIUM TEST FACILITY REQUIREMENTS}

To meet the anticipated requirements for design, development, verification and qualification described in Section 3.0, the availability of a recirculating helium test facility is required. This facility should satisfy the following general requirements:

- It must be capable of providing helium flow at pressures, temperatures and rates typical for MFE blanket designs. These flow conditions must he control?able over an operational range typical of [DP blankets.

- It must be capable of volumetric heat generation within the blanket test module at rates typical for EPR blankets. The distribution of the heat generation should simulate the exponential radial decay profile of a real magnetic fusion reactor.

- It must be capable of heating the first wall to prototypical temperatures.

- It must be sized such that a representative full-scale section of the first wall and blanket (i.e., the largest module of any of the currently considered designs) can be cooled and tested.

- It must be sufficiently versatile to test blanket modules of different design concepts equally well.

- It must be able to operate under transient conditions simulating the periodic plasma burn of a magnetic fusion reactor.

- The facility must be equipped to reject the entire heat load (generated during testing) to the environment (atmosphere, cooling tower, etc. i.

- Automatic controls must be available to allow accurate simultaneous simulation of all facility variables during transient experimentation.

- The facility should allow for the later addition of ancillary coolant systems using alternate fluids (liquid metal, water, molten salts, etc.) to enable studying the features of blankets or associated equipment using these coolants or combined coolants. 
- The facility must be instrumented to allow detailed steady-state and transient observations and measurements for a thermal, hydraulic and stress evaluation. An automatic data acquisition system should be available for scanning and recording the large quantity of data anticipated in typical testing.

- The facility should have flexibility to use air at low temperature to test hydraulic performance of components.

Since one of the principal purposes of this facility is "hands-on" testing and development, its operation should not be encumbered by the presence of radioactive contamination in the recirculating helium system or in the immediate surroundings. It should not be required to test radioactive assemblies or equipment which could theoretically contaminate the system or the immediate vicinity, thereby reducing the system's utility for the type of R\&D for which it is intended.

\subsection{FACILITY SIZE CONSIDERATIONS}

According to present MrE Program plans, experimental power reactors of the Tokamak type will be built and operated before any commitment will be made for a large demonstration plant. Therefore, test facility requirements will be directed principally at these reactors. This will result in a much smaller facility than needed otherwise and will thereby considerably reduce construction time, building costs, and operational expenses. It is expected that the small test facility proposed in this document will suffice for at least 10 years. During this time period, it is expected that considerable progress will be made in the development of MFE reactor designs and the definition of associated problems. With this information, it will be more possible to determine the need for a more advanced facility for developing the next generation of demonstration reactors than is now possible. If a more advanced facility becomes desirable, the experience, equipment and services made available through the construction of this smaller facility would be a valuable asset to the MFE program to enable the design and construction of such a facility with minimum time and cost. 


\subsection{REQUIRED FACILITY PARAMETERS}

From the general facility requirements specified in Section 5.0, the test facility should be capable of testing at least one EPR module at helium flows, temperature and pressures consistent with prototype values. It should have sufficient electric energy available to allow the simulation of first wall heat loads and internal heat generation by plasma torches, ohmic heating or other means.

The anticipated operating conditions for the blankets of all currently active EPR and DPR designs were summarized in Table 1. These data are presented in Table 2 in terms of parameters applicable to one module for the various EPR designs. The test facility under consideration should be capable of simulating these modular values.

It can be seen that the Argonne National Laboratory (ANL) and Oak Ridge National Laboratory (ORNL) requirements are quite similar, whereas the General Atomic Company (GA) design has significantly lower requirements because of its greater number of individual modules. The hybrid, on the other hand, poses much higher flow requirements because its blanket has a much higher power density.

Whereas EPR modules could easily be tested at full scale, it was assumed that hybrid modules would be tested at a reduced scale. A one-fourth volumetric ( $2 / 3$ linear) scale was selected to reduce heating requirements to a range consistent with the EPR requirements. The fourth column in Table 2 shows the requirements for such a one-fourth scale hybrid blanket modute.

The last row in Table 2 presents the proposed facility characteristics that would be responsive to the specified testing requirements. The facility's temperature and pressure requirements are consistent with those for the EPRs. However, it was felt that it would increase the cost of the facility inordinately, if the presently assumed operating temperature of $816^{\circ} \mathrm{C}$ for the hybrid blankets were to be matched in the test facility. Since it is quite possible that this temperature may have to be revised downward under the pressure of more realistic engineering design limitations, the $600^{\circ} \mathrm{C}$ temperature capability for the proposed facility appears to be adequate. 


\section{TABLE 2. Technical Requirements for Testing Single Blanket Modules(a)}

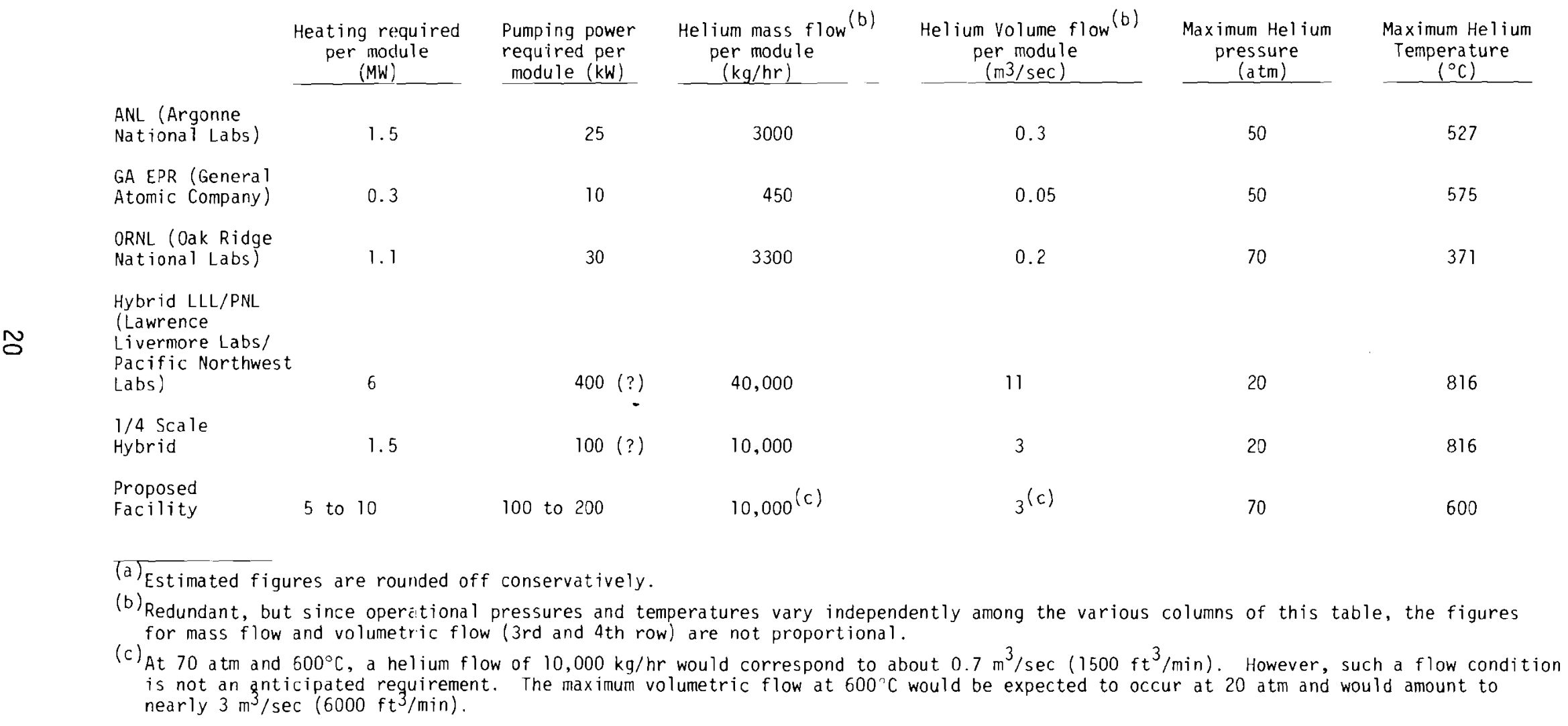


A minimum helium mass flow of $10,000 \mathrm{~kg} / \mathrm{hr}$ at $70 \mathrm{~atm}$ would satisfy the needs for a one-fourth scale model test of the hybrid reactor. A maximum capacity of $100,000 \mathrm{~kg} / \mathrm{hr}$ is recommended to allow for evaluation of blankets and components at non-normal conditions, enable ample bypass flow to ensure stable operating conditions, and provide a contingency to meet the possible testing requirements of new or alternate blanket designs. The power required for circulating this amount of helium through the test module depends on the flow resistance in the module and in the other components of the circuit, on the efficiency of the circulator and its drive, etc. It was estimated that 1000 to $2000 \mathrm{~kW}$ would be sufficient for this purpose.

The power requirements for the internal heating of the largest module would be in the order of several megawatts. It is recommended that at least $3 \mathrm{MW}$ be available for initial testing. In addition, it should be possible to expand the power availability to approximately $10 \mathrm{MW}$ to accommodate the expected increases in power density of future fusion blankets.

The test facility should be designed such that it could be operated also with air at lower temperatures and pressures. This may often simplify test procedures and thus save operational costs. Since helium at $600^{\circ} \mathrm{C}$ and $50 \mathrm{~atm}$ has the same kinematic viscosity as air under ambient conditions, Reynolds numbers $\left(\mathrm{N}_{\mathrm{Re}}\right)$ for air tests with the same volumetric flow rates equal those for helium tests at $600^{\circ} \mathrm{C}$ and $50 \mathrm{~atm}$. This example shows that $N_{R e}$ simulation by using air instead of helium may be fairly easily accomplished.

\subsection{EXISTING FACILITIES}

Helium-cooled test facilities in the U.S. and Europe were surveyed to determine those with capabilities consistent with the requirements described in Sections 4.0, 4.1 and 4.2.

It was found that no helium-cooled test facilities suitable for testing MFE helium-cooled blanket modules are currently available in the U.S. On the other hand, a number of such facilities exist in Europe. The exclusive availability of such facilities in Europe is the result of a greater emphasis 
placed on gas-cooled fission reactor development in Europe than in the U.S. of the world's roughly 45 gas-cooled power reactors, only two were built in the U.S.--Peach Bottom 1 and Fort St. Vrain, both designed and built by GA. Thus, a viable industry program for gas-cooled reactors never really got off the ground in the U.S. and, so far, GA has mainly used the European facilities for testing their reactor components. Because the future of gas-cooled reactors is more uncertain now than ever, there are also no longer any plans for building helium flow loops.

Table 3 lists the major gas facilities considered in this survey and some of their important operating parameters. When comparing the parameters for the various facilities with the requirements for a blanket test facility described in Section 4.2, it can be seen that several would meet the requirements.

One particularly attractive facility is the new Hochtemperatur-HeliumVersuchsanlage (HHV) facility at Jülich, Germany. The HHV facility, shown in Figure 4, is considered the most advanced high temperature hel ium loop anywhere. It is to be commissioned in 1977 at Kerforschungs-Anlage (KFA). It was originally conceived in the early l970s as a loop for testing high temperature gas-cooled reactor components, specifically those of the direct cycle design with fully integrated gas turbines. Although further development of this reactor type was suspended in Germany in October 1975, the HHV (already well advanced in construction) was specifically excluded from this decision, since it was realized that a facility of this type and versatility would be very useful for testing components of other gas-cooled reactors (including fusion reactors). This government-owned facility is quite unique because it combines high temperatures $\left(1000^{\circ} \mathrm{C}\right.$ ) and high pressures $(50 \mathrm{~atm})$ with large flow rates $(800,000 \mathrm{~kg} / \mathrm{hr}$ of helium). It was designed and built by Brown Boveri. Its original cost, estimated at $\$ 30$ miiiion, has been exceeded, however, because of inflationary effects.

The only U.S. facility with parameters possibly attractive for MFE blanket testing is the GA gas circulator test loop at San Diego. This is a special-purpose loop constructed for gas circulator testing only. Its 


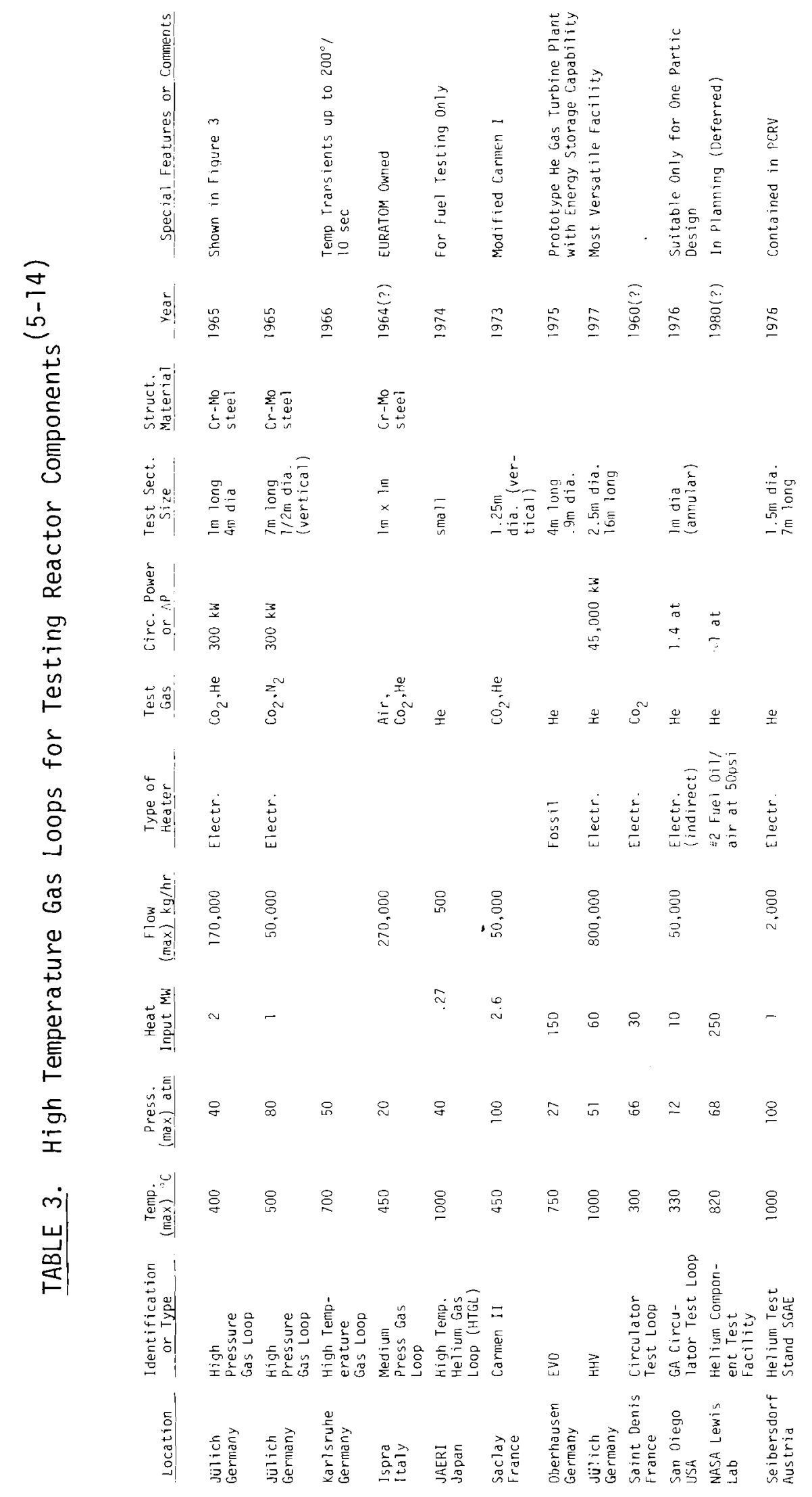




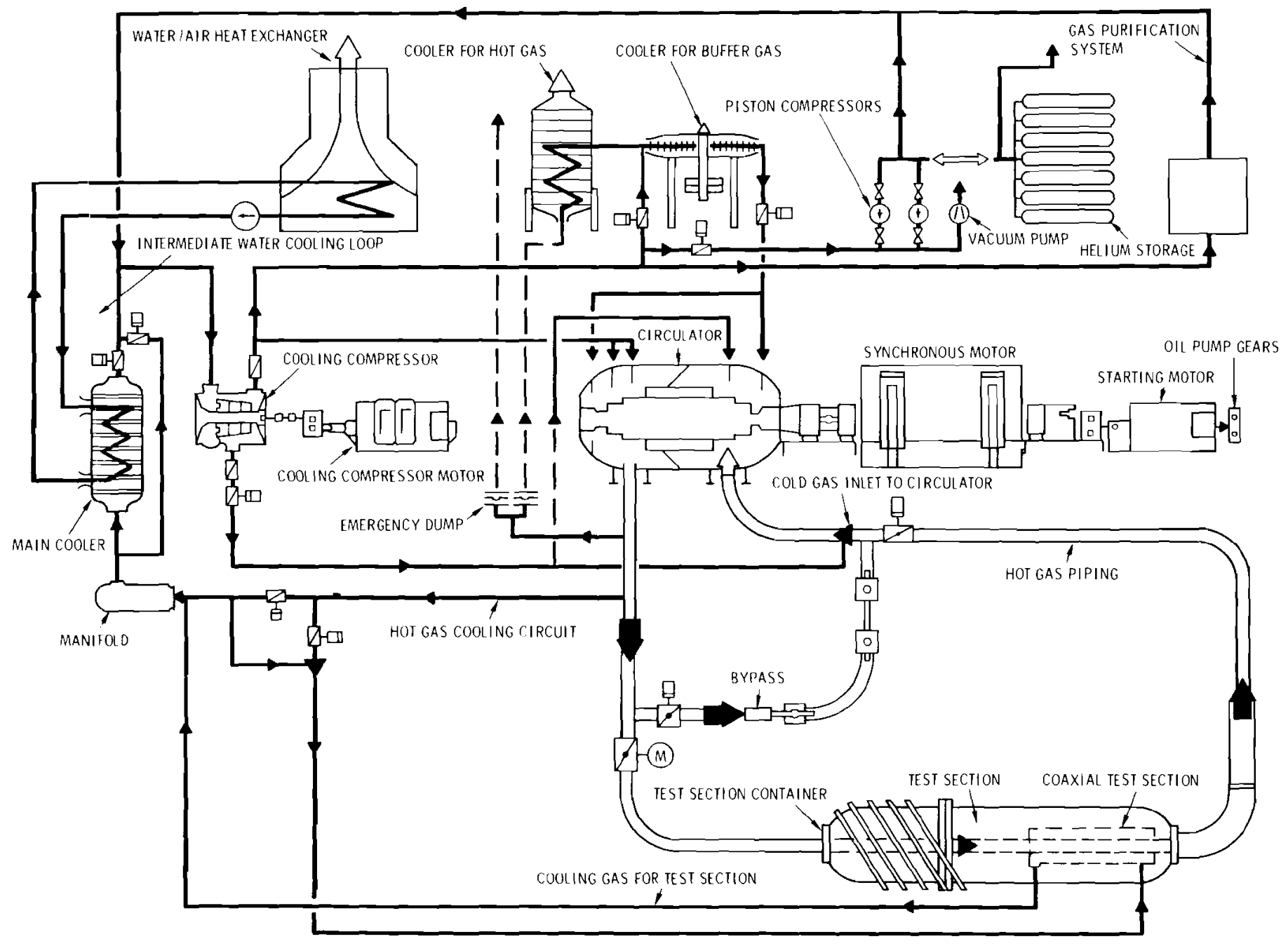

FIGURE 4. HHV Facility Flow Diagram 
configuration is such, however, that extensive revisions of the facility would have to be performed to adapt it to blanket testing. Therefore, it was concluded that such testing would not be feasible in this facility.

In conclusion, helium facilities adequate for steady-state MFE blanket testing may presently exist in Europe. However, it is apparent that none of these facilities has the capacity to perform transient testing without extensive modifications. No determination was made regarding the availability of these facilities for modification and testing. However, it is doubtful if these facilities would be available without complication from conflicting priorities, proprietary matters and political interests.

\subsection{ALTERNATE MEANS OF PROVIDING RESEARCH CAPABILITIES: OTHER FACILITY CONCEPTS}

The problem areas addressed in this report are restricted specifically to thermal, hydraulic and mechanics classifications. It may be possible to address these problem areas in a larger, general facility which is capable of testing multiple aspects of several or a 11 designs proposed to date. However, a facility to consider all engineering problems (including radiation damage) of all proposed designs appears to be far too complex to warrant serious consideration at this time. Based on past experience with test facilities and procedures used in the development of new complex technologies (e.g. in the aerospace field and also in the development of various fission reactor projects), experimental facilities were initially tailored to solving specific limited problem areas. Thus, a series of various specialized test facilities evolved before the end product was eventually put through final qualification testing.

In particular, it would appear very unrealistic to plan heat transfer and fluid dynamic testing in Tokamak test reactors. It seems to be highiy uneconomical and time consuming to attack the entire gamut of engineering problems in such an expensive and complex facility. 
Test reactors and facilities like the proposed Tokamak Engineering Test Reactor (TETR) and Fusion Energy Research Facility (FERF) certainly are required. However, for most of the required advariced system verification testing, smaller, simpler and less expensive nonnuclear facilities would undoubtedly suffice.

Consequently, limiting test facility requirements to such a size and complexity to be responsive to the design engineering needs of the initial EPRs would have the following advantages:

- less initial cost and operating expense

- more immediate availability than a large complex facility

- the facility could serve as a learning device to gain experience for the eventual building of a large-size facility. 


\subsection{RECOMMENDED HELIUM-COOLED BLANKET DEVELOPMENT FACILITY}

In Section 3.0 it was observed that the adequate cooling of the entire blanket structure (not just of the first wa11) requires extensive study of the thermal-hydraulic problems, particularly under transient or off-design conditions. Thermal stresses associated with a complex three-dimensional temperature distribution in the odd shape of the blanket structural components with their intricate cooling passages and their internal heat generation will be so complex that a mere analytical determination of the temperatures and the resulting stresses may be quite unreliable. Therefore, the MFE community has recommended that such complex engineering problems be solved with the aid of model testing in a special facility.

At a conference at Brookhaven National Laboratory, (1) the design of a blanket for MFE power reactors was critically assessed for the first time by those U.S. fusion program participants active in blanket design for several years. As one of the most urgent future requirements for blanket engineering, it was recommended that a blanket test facility be obtained for the purpose of qualifying certain promising MFE blanket design concepts by verification tests.

Design supported by tests is a well proven approach, and it has been common practice to perform extensive development and verification testing with all types of reactors (LWRS, LMFBRS, HTGRs, etc.). Experience has always substantiated the need for such testing before a viable design could be established for the various fluid-thermal reactor components.

In Section 4.3, it was noted that no facility suitable for testing of MFE blanket assemblies exists in the U.S., but several facilities have been built in Europe. It may be desirable to do some testing in these European facilities if they are available on a timetable consistent with the MFE program schedule. However, during the final design, development and initial operation of the EPRs, it is likely that a 
facility would be required on a continuous basis for several years. The continuous availability of the European facilities over such a period of time appears unlikely since they are important parts of the fission and fusion power development programs in the countries where located. Furthermore, it would be difficult to safeguard classified or industrial proprietary developments in these facilities. Therefore, it appears to be highly undesirable to plan to use foreign facilites for a major national energy project in which crucial design features of fusion reactor demonstrations wil1 be developed and verified.

In view of the need for a helium-cooled blanket test facility in this country, it is recommended that preliminary design of such a facility start immediately such that it can be available for research and development activities in FY-1983.

\subsection{SCOPE OF TESTING CAPABILITY}

It is recommended that this facility be sufficiently versatile to enable performance testinc of a variety of MFE cooling systems and mechanical components in addition to providing the capability for blanket development, verification and qualification. Although specific development requirements have not been identified for many types of mechanical components, it wil1 stil1 be required to conduct qualification testing on these components before their incorporation into a final reactor design. The availability of the capability to perform such testing (and development, if necessary) wi11 expedite the eventual design process and increase the degree of confidence in the operability of the final desian.

The proposed facility will be designed to address problem areas including:

1. blanket development: thermal-hydraulic performance, thermal and mechanical stresses, steady-state and transient behavior;

2. material behavior: corrosion and material transport in a flowing contaminated helium environment at high temperatures; 
3. vibrations: natural frequencies, forcing functions, fretting, wear and fatigue;

4. thermal insulation: performance tests;

5. ducting, headers and manifolds: same problems as indicated in 1;

6. gaskets and seals: performance in high temperature and pressure helium;

7. circulator design: bearing and seal design, performance, thermal and mechanical stresses (model testing);

8. helium heat exchangers (steam generators): performance, vibration, etc. ;

9. thermal storage systems: performance tests (models);

10. helium purification system: performance;

11. instrumentation: performance tests, calibration, lifetime.

\subsection{GENERAL FACILITY DESCRIPTION}

The schematic drawing for the proposed facility is given in Figure 5. The facility will initially consist of two flow loops: a recirculating helium test loop and a cooling water loop. The capability will be provided for the later addition of other cooling loops (molten salt, lithium, etc.) if the testing program requires this.

The recirculating helium loop will consist of a blower, heat exchanger, blower bypass valve, the test assembiy and interconnecting piping. The blower will be driven by a variable-speed electric motor and will be capable of supplying $100,000 \mathrm{~kg} / \mathrm{hr}$ of helium to the test assembly at a maximum temperature and pressure of $600^{\circ} \mathrm{C}$ and $70 \mathrm{~atm}$, respectively. Due to heat generation in the test section simulating the deposition of fusion energy, the helium temperature at its discharge wili be elevated with regard to inlet. This hot discharged helium will be cooled in the heat exchanger before being returned to the suction of the blower. A bypass valve around the test assembly will be provided to assist in attaining 


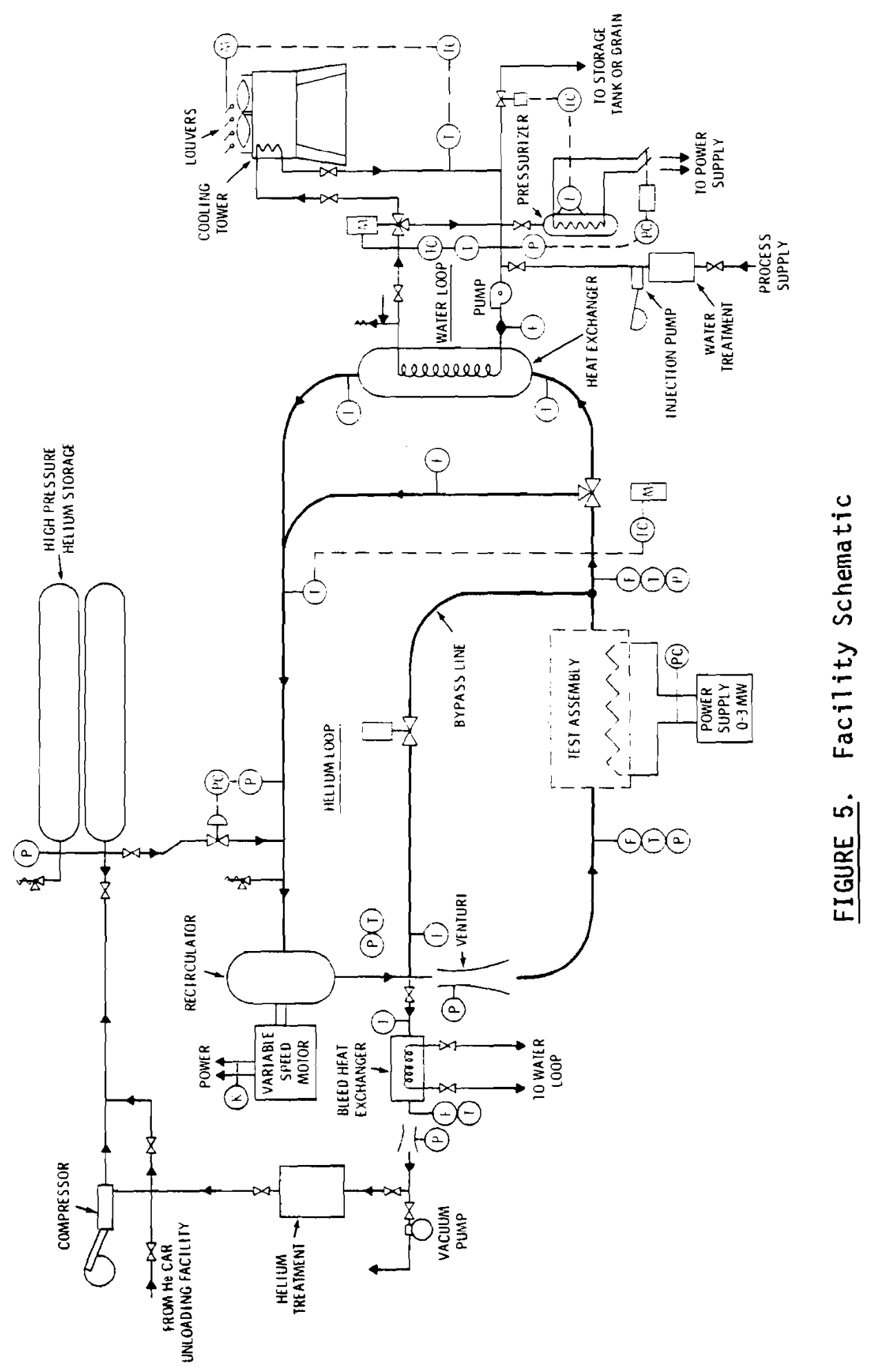


and maintaining stable flow rates through the loop, especially at low flow rates. Venturis will be emplaced at the test assembly inlet and the bypass line to measure helium flow rates.

Helium purity will be maintained by a "feed and bleed" system. Helium will be bied from the loop, cooled as required and purified in an external modulator treatment unit. The main impurities that will require removal include hydrogen, oxygen and carbon dioxide. Following treatment, it will be recompressed and returned to the helium storage tank. To replace the bled-off helium, high purity gas from the storage vessel will be introduced into the system through a pressure regulator. A vacuum pump will be provided to evacuate the system prior to charging with helium. Normal loop heatup will be accomplished through fluid friction and test assembly heating.

The water loop will provide cooling to the primary heat exchanger and to portions of certain specific blanket designs that incorporate water cooling. Water will be circulated in the closed, pressurized 10op by a pump with a variable-speed motor. The pump will take the cooled water from the cooling tower and deliver it to the primary heat exchanger. The hot water from the heat exchanger will be returned to the cooling tower. The cooling tower will be a conventional "fin-fan" unit. An electrically heated pressurizer will be provided at the suction of the pump to maintain system pressure at the desired value. The temperature of the water supplied to the main heat exchanger will be controlled by the threeway, flow-balanced valve which bypasses a fraction of the coolant around the cooling tower.

The water system will be designed for $300 \mathrm{psi}$ and $400^{\circ} \mathrm{F}$. These operating conditions may be revised later to accommodate new blanket designs which need water at higher temperature at pressures for component cooling. Water pH and oxygen content will be maintained within specified limits by chemical injection. System piping will be carbon steel; the cooling tower heat exchangers will be admiralty metal with aluminum fins. 
A minicomputer with automatic data acquisition capability will be supplied to control facility process variables and to measure the variables indicated in Figure 5. Provisions will be included for approximately 150 thermocouple temperature measurements, 50 resistance thermometer measurements and 75 strain gage pressure ( $P$ and $\Delta P$ ) measurements at the test assembly.

A low voltage, high current power supply will be provided to enable the simulation of fusion heat deposition in the test assembly by ohmic heating. This simulation will be accomplished as discussed in Section 5.3.

The facility should be located in a separate structure adjacent to, but separate from, the building containing offices, shops, change and sanitary facilities, and utilities. This separation is desirable to limit interference of normal activities within the building by the high-noise and high-temperature environment of the gas facility.

\subsection{BLANKET AND FIRST WALL SIMULATION}

Considerable planning and conceptual design activities must be performed before a valid and defensible scheme for test assembly heating can be finalized. The principal problem is in simulating both the intense first surface thermal loading and the rapid special decay of internal heat generation in the direction away from the plasma. Perhaps a11 spatial and temporal features of, the internal heating may not be required to verify the design and analytical models. However, for qualification testing, it appears highly desirable to simulate as many features of the heating pattern as feasible. In the following paragraphs, several speculative methods of providing this heating effect will be discussed.

One method to produce a test assembly temperature distribution approximating the real case is to distribute electrical resistance elements over the external and internal surfaces of the blanket test assembly. This could be achieved in various ways. For example, the heating elements could be arranged in a configuration of varying density 
(pitch), and/or the various elements could be supplied individually with different, predetermined amounts of electric power. The resulting temperature distribution within the blanket test module would be checked with a series of internally placed thermocouples. After the desired temperature distribution is attained, thermal strain in the assembly can be determined by strain gages affixed to test assembly surfaces.

A second method is to heat the first wall and blanket surfaces by passing a high amperage electrical current through them directly or through resistance films deposited on the surfaces but isolated from them electrically. Such a film can be applied by flame or plasma torch techniques, with a ceramic insulator applied first, followed by an even or variable thickness metallic resistance layer. This method will not enable simulations of the internal heat generation; however, it may be adequate to verify computer methods and maximum stress levels.

Yet another method of supplying surface heating is by employing a plasma jet or battery of jets impinging on the first wall surface. This scheme has disadvantages similar to the previous method. However, it is somewhat more appealing because of the absence of the awkward and fragile surface coatings.

Such schemes, of course, would simulate only the thermal heat flux but not the specific effects on the first wall by neutrons, photons, ions and atoms. Therefore, the effects resulting from this type of loading cannot be evaluated in the proposed (nonradiation type) facility. Other specialized facilities must be used for this purpose.

In all testing it is recommended that the first wall and blanket module be simultaneously performed to ensure that any potential interactions are included. For the GA design the blanket module must absorb and carry away the heat radiated from the backside of the first wall. In the case of first wall water cooling as planned both in the ANL and ORNL facilities, the interaction will be much less. However, because the inclusion of water-cooling capabilities of the first wall does not pose any significant technical problems for the test facility (water flow rates, pressures and temperatures are quite low), such testing is 
nevertheless recommended. It would thus guarantee an integrated test of the entire first wa11-blanket configuration, as far as thermal and structural response during transients or during on/off conditions are concerned. For tests involving only water cooling effects on the first wall, other, more suitable, facilities should be used. 


\section{REFERENCES}

1. J. R. Powel1, ed., Proceedings of the Magnetic Fusion Energy Blanket and Shield Workshop. ERDA-6-117-1, Energy Research and Development Administration, Washington, DC, 1976.

2. M. A. Hoffman et al., Review of Heat Transfer Problems Associated with Magnetical1y-Confined Fusion Reactor Concepts. UCRL-78036, Lawrence Livermore Laboratories, Livermore, CA, 1976.

3. D. W. Kearny et a1., Heat Transfer Problems in Noncircular Tokamak Experimentà 1 Power and Demonstration Reactors. GA-A13857, General Atomic Company, San Diego, CA 92138, 1976.

4. J. R. Young and B. F. Gore, Reference Commercial Fusion Power Plants. BNWL-2014, Battelle, Pacific Northwest Laboratories, Richland, WA 99352 , September 1976.

5. H. Grosse and F. Scholz, "High Pressure Gas Tunne1." Kerntechnik. 7 $: 150-158,1965$.

6. K. H. Presser and F. Scholz, "Gas-Cooled, Fuel Element Test Rigs." Kerntechnik. 7:186, 1965.

7. "Gas Loops for Development and Testing of Fuel Elements." Kerntechnik. $7: ? 86,1965$.

8. "Experimental Loops in Nuclear Research Establishments." Kerntechnik. 7:184-185, 1965 .

9. H. Shimora et a1., "Thermal and Hydraulic Performance of High Temperature Helium Gas Loop." ASME paper 74-WA/HT 3, American Society of Mechanical Engineers, New York, NiY, 1974.

10. J. Chaboseau et a1., "HTGR Component Testing." ANS Conf. 740501 on Gas-Cooled Reactors: HTGR and GCFBR, Gatlinburg, TN, 1974.

11. G. Noack et a1., "Grossversuch an Komponenten von HTR-Einkreisanlagen." Nuclex paper 2-8, 1975.

12. HHT Project, Hochtemperatur-Helium-Versuchsanlage (HHV), HHT3, KFA Jülich, Germany, 1972.

13. V. R. Larson et a1., "Helium Heater Design for the Helium Direct Cycle Component Test Facility," AIAA paper 75-1262, American Institute of Aeronautics and Astronautics.

14. K. Fritz et al., The Development of HTR Components. SGAE BER 2623, Oesterreichis Studiengesellschaft Fuer Atomenergie G.mbH, Seibersdorf, Austria, 1976. 


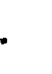


No. of

Copies

OFFSITE

A. A. Churm

ERDA Chicago Patent Group

9800 S. Cass Ave.

Argonne, IL 60439

J. M. Williams

ERDA Division of Magnetic

Fusion Energy

Washington, DC 20545

3 F. E. Coffman

ERDA Division of Magnetic

Fusion Energy

Washington, DC 20545

K. M. Zwilsky

ERDA Division of Magnetic

Fusion Energy

Washington, DC 20545

J. Baublitz

ERDA Division of Magnetic

Fusion Energy

Washington, DC 20545

J.W. Beal

ERDA Division of Magnetic

Fusion Energy

Washington, DC 20545

L. Bogart

ERDA Division of Magnetic

Fusion Energy

Washington, DC 20545

M. M. Cohen

ERDA Division of Magnetic

Fusion Energy

Washington, DC 20545

H. S. Cullingford

ERDA Division of Magnetic

Fusion Energy

Washington, DC 20545
No. of

Copies

E. N. C. Dalder

ERDA Division of Magnetic

Fusion Energy

Washington, DC 20545

J. F. Decker

ERDA Division of Magnetic

Fusion Energy

Washington, DC 20545

C. R. Finfgeld

ERDA Division of Magnetic

Fusion Energy

Washington, DC 20545

J. N. Grace

ERDA Division of Magnetic

Fusion Energy

Washington, DC 20545

E. E. Kintner

ERDA Division of Magnetic

Fusion Energy

Washington, DC 20545

R. N. Kostoff

ERDA Division of Magnetic

Fusion Energy

Washington, DC 20545

J. V. Martinez

ERDA Division of Magnetic

Fusion Energy

Washington, DC 20545

J. 0. Neff

ERDA Division of Magnetic

Fusion Energy

Washington, DC 20545

T. C. Reuther

ERDA Division of Magnetic

Fusion Energy

Washington, DC 20545 
5 B. G. Twining

ERDA Division of Magnetic

Fusion Energy

Washington, DC 20545

P. M. Stone

ERDA Applied Plasma Physics

Program

Washington, DC 20545

D. D. Mahlum

ERDA Division of Biomedical and Environmental Research

Washington, DC 20545

Assistant Director for Technology

ERDA Division of Reactor Research and Development Washington, DC 20545

Chief, Fuel Systems Branch

ERDA Division of Reactor

Research and Development Washington, DC 20545

ERDA Technical Information Center

2 Director, ANL Fusion Power Program, Building 208

Argonne National Laboratory 9700 S. Cass Ave.

Argonne, IL 60439

M. S. Kaminsky

Argonne National Laboratory

9700 S. Cass Ave.

Argonne, IL 60439

V. H. Maroni

Argonne National Laboratory 9700 S. Cass Ave.

Argonne, IL 60439

P. M. Persiani

Argonne National Laboratory 9700 S. Cass Ave.

Argonne, IL 60439
M. Petrick

Engineering and Technology Division

Argonne National Laboratory

9700 S. Cass Ave.

Argonne, IL 60439

W. E. Parkins, Manager

Atomics International

Component Engineering and Technology Division

North American Rockwell

P.0. Box 309

Canoga Park, CA 91304

2 Chairman, Department of Applied Sciences

Brookhaven National Laboratory

Associated Universities

Upton, NY 11973

Associate Chairman for Chemistry and Materials Programs, Department of Applied Sciences

Brookhaven National Laboratory Associated Universities

Upton, NY 11973

A. N. Goland

Brookhaven National Laboratory Associated Universities

Upton, NY 11973

D. Gurinsky

Brookhaven National Laboratory ERDA Brookhaven Area Office Upton, NY 11973

S. Pearlstein Brookhaven National Laboratory ERDA Brookhaven Area Office Upton, NY 11973

J. R. Powel1

Brookhaven National Laboratory ERDA Brookhaven Area Office Upton, NY 11973 
No. of

Copies

A. J. Impink, Jr.

Carnegie Melion University

Pittsburgh, PA 15213

R. A. Gross

Columbia University

Plasma Physics Laboratory

236 SW Mudd Bldg.

New York, NY 10027

Program Manager for Fusion Power

Electric Power Research

Institute

$3412 \mathrm{Hillview} \mathrm{Ave.}$

Palo Alto, CA 94304

W. C. Gough

Electric Power Research Institute

3412 Hillview Ave.

Palo Alto, Cf. 94303

2 Manager, Fusion Engineering Department

Gulf General Atomic Co.

P.0. Box 81608

San Diego, CA 92138

G. R. Hopkins

Gulf General Atomic Co.

P.0. Box 81608

San Diego, CA 92138

Z. Sabri

Nuclear Engineering Department

261 Sweeney Hall

Iowa State University

Ames. IA 50010

H. K. Forsen

Jersey Nuclear Company

777 106th Ave., NE

Bellevue, WA 98004
No. of

Copies

R. Borg

Lawrence Livermore Laboratory P.0. Box 808

Livermore, CA 94550

T. K. Fowler

Lawrence Livermore Laboratory P.0. Box 808

Livermore, CA 94550

A. C. Haussmann

Lawrence Livermore Laboratory

P.0. Box 808

Livermore, CA 94550

A. L. Hunt

Lawrence Livermore Laboratory P.0. Box 808

Livermore, CA 94550

R. Moir

Lawrence Livermore Laboratory P.0. Box 808

Livermore, CA 94550

C. J. Taylor

Lawrence Livermore Laboratory

P.0. Box 808

Livermore, CA 94550

L. L. Wood

Lawrence Livermore Laboratory

P.0. Box 808

Livermore, CA 94550

Division Leader, CTR Division Los Alamos Scientific Laboratory

P.C. Box 1663

Los Alamos, NM 87544

D. J. Dudziak

Los Alamos Scientific

Laboratory

P.0. Box 1663

Los Alamos, NM 87544 
No. of

Copies

D. B. Henderson

Los Alamos Scientific Laboratory

CTR Division

P.0. Box 1663

Los Alamos, NM 87544

L. Stewart

Los Alamos Scientific Laboratory

CTR Division

P.0. Box 1663

Los Alamos, NM 87544

B. Coppi

Department of Physics

Massachusetts Institute of Technology

Cambridge, MA 02139

0. K. Harling

Massachusetts Institute of Technology

Cambridge, MA 02139

L. Lidsky

Department of Nuclear Engineering

Massachusetts Institute of Technology

Cambridge, MA 02139

D. Rose

Massachusetts Institute of Technology

Cambridge, MA 02139

R. E. Stickney

ivechanicai Engineering

Massachusetts Institute of Technology

Cambridge, MA 02139

Manager, Technology

Applications and Development

Mound Laboratory

P.0. Box 32

Miamisburg, $\mathrm{OH} 45342$
No. of

Copies

J. J. Reinmann

NASA--Lewis Research Center

2100 Bookpark Rd.

Cleveland, $\mathrm{OH} 44135$

V. Arp

National Bureau of Standards

Cryogenics Division

Boulder, CO 80302

Director, Metals and Ceramics Division

Oak Ridge National Laboratory

P.0. Box $Y$

Oak Ridge, TN 37830

Program Manager, Fusion

Reactor Technology Program

B1dg. 9204-1

Oak Ridge National Laboratory

P.0. Box $Y$

Oak Ridge, TN 37830

J. L. Scott, Manager

Magnetic Fusion Energy

Materials

Metals and Ceramics Division

Bldg. 4500 SM, S-178

P.0. Box $X$

Oak Ridge, TN 37830

A. P. Fraas

Oak Ridge National Laboratory

P.0. Box $Y$

Oak Ridge, TN 37830

J. Rand MCNally, Jr.

Oak Ridge National Laboratory

F.Û. B̈ox Y

Oak Ridge, TN 37830

D. Steiner

Oak Ridge National Laboratory P.O. BoX Y

Oak Ridge, TN 37830 
R. Werner

Oak Ridge National Laboratory

P.0. Box X

Oak Ridge, TN 37830

R. Cooper

Physics Internationa 1

2700 Merced St.

San Leandro, CA 94577

R. A. Huse

Public Service Electric and Gas Co.

80 Park Place

Newark, NJ 07101

H. Perkins

Department of Chemistry

Princeton University

Princeton, NJ 06540

Director, Plasma Physics Laboratory

Princeton University

Box 451

Princeton, NJ 08540

Project Manager, TFTR

Plasma Physics Laboratory

Princeton University

Box 451

Princeton, NJ 08540

R. G. Mitis

Plasma Physics Laboratory

Princeton University

Box 451

Princeton, NJ 08540

E. C. Tånner

Plasma Physics Laboratory

Princeton University

Box 451

Princeton, NJ 08540
2

W. Bauer

Division Supervisor of

Physical Research

Sandia Laboratories

Livermore, CA 94550

M. Kristiansen

Texas Tech. University

Lubbock, TX 79409

A. F. Haught

United Aircraft Research Laboratory

United Aircraft Corp.

East Hartford, CT 06108

Head, Thermo Structura 1

Materials Branch

U.S. Nava 1 Research Laboratory

Metallurgy Division

Code 6390

Washington, DC 20390

L. Levine

U.S. Nava 7 Research Laboratory Washington, DC 20390

C. Z. Serpan, Jr.

U.S. Naval Research Laboratory

Washington, DC 20390

F. Chen

UCLA School of Engineering and Applied Science

Boelter 7731

Los Angeles, CA 90024

A. J. Lichtenberg University of Ca? ifornia

Electronics Research Laboratory College of Engineering

Berkeley, CA 94720 
No. of

Copies

C. D. Hendricks

University of Illinois

Nuclear Engineering Laboratory

Urbana, IL 61801

T. Kamash

University of Michigan

Nuclear Engineering Department

Ann Arbor, MI 48105

Dean Abrahamson

University of Minnesota

School of Public Affairs

Social Science Building/308

Minneapolis, MN 55455

W. G. Davey

University of Texas

Department of Physics

Austin, TX 78712

E. L. Draper, Jr.

University of Texas

Department of Physics

Austin, TX 78712

W. E. Drummond

University of Texas

Department of Physics

Austin, TX 78712

A. Hertzberg

University of Washington

Aerospace Research Laboratory

316 Guggenheim

Seattle, WA 98105

A. L. Babb

University of Washington

Nuclear Engineering Department

Seattle, WA 92105

R. Conn

University of Wisconsin

Nuclear Engineering Department

Madison, WI 53706
No. of

Copies

G. L. Kulcinski

University of Wisconsin

Nuclear Engineering Department

Madison, WI 53706

C. W. Maynard

University of Wisconsin

Nuclear Engineering Department

Madison, WI 53706

D. Lichtman

Department of Physics

University of Wisconsin

Milwaukee, WI 53201

E. E. Donaldson

Washington State University

Department of Physics

Pullman, WA 99163

Manager, Fusion Power Systems Department

Westinghouse Electric Corp.

P.0. Box 355

Pittsburgh, PA 15230

ONSITE

3 ERDA Richland Operations Office
W. A. Burns
P. G. Holsted
H. E. Ransom

Rockwel1 Hanford Operations

J. D. Kaser

3 Hanford Engineering Development Laboratory

Manager, Materials

Engineering

D. G. Doran

H. H. Yoshikawa 
No. of

Copies

99

Battel le-Northwest

D. T. Aase

F. W. Albaugh

G. S. Altison

T. W. Ambrose

D. G. Atteridge

M. C. Bampton

J. L. Bates

H. J. Bomelburg (3)

J. L. Boyd

J. L. Brimhall

R. L. Brodzinski

R. J. Brouns

L. R. Bunnel 1

S. H. Bush

N. E. Carter

T. D. Chikalla

R. G. Clark

J. M. Creer

J. P. Crewdson

S. D. Dahlgren

L. J. Defferding

D. E. Deonigi

R. L. Dillon

D. A. Dingee (2)

J. W. Finnigan

D. E. Fitzsimmons

J. C. Fox

J. J. Fuquay

J. E. Garnier

J. D. Goodenough

B. F. Gore

W. J. Gray

C. R. Hann

A. J. Haverfield

U. P. Jenquin

A. B. Johnson, Jr.

B. M. Johnson
No. of

Copies

R. H. Jones

T. J. Kabele

W. S. Kelly

C. J. Knoll

B. R. Leonard, Jr.

R. C. Liikala

M. A. Mckinnon

R. P. Marsha 11

W. S. Matsumoto

R. A. McCann

R. D. Nelson

D. R. Newman

R. E. Nightingale

D. E. Olesen

L. T. Pedersen

R. T. Perry

L. L. Rader

W. D. Richmond

L. C. Schnid

J. B. Schuette

E. P. Simonen

R. I. Smith

D. L. Styris

A. M. Sutey (10)

V. L. Teofilo

G. L. Tingey

M. T. Thomas

R. D. Tokarz

D. S. Trent

M. Vagins

R. E. Westerman

T. Wilke

H. J. Willenberg

L. D. Williams

F. R. Zaloudek (10)

Technical Publications (5)

Technical Information 
